\title{
The Pandemic Pivot: The Impact of COVID-19 on Mathematics and Statistics Post-Secondary Educators
}

\author{
Sonia Rey Lopez, Glenna R. Bruun, Michael J. Mader, Robert F. Reardon \\ Texas State University \\ USA
}

\begin{abstract}
The COVID-19 pandemic disrupted the face-toface mode traditionally used to engage learners in higher education. A majority of university faculty who were unfamiliar or untrained in teaching online courses were obliged to transform in-person courses to online instruction in the spring of 2020. This exploratory study considers the experience before and after the rapid pivot to online teaching, specifically related to mathematics and statistics instructors; subjects traditionally challenging to reproduce online. A Likert-style questionnaire was administered at four central Texas institutions of higher education to learn about the challenges math instructors encountered. An open-ended response was also included in the survey to add clarity and allow respondents the opportunity to provide commentary in their own words, creating a fuller picture of online instruction during times of interference. Results highlight major challenges for instructors when transitioning from established face-to-face courses to online instruction. The study uncovers the impact on faculty related to technology use, classroom interaction, life/work balance, and concerns about learning outcomes. It also provides a glimpse into the personal and professional disruption associated with this transition. The study concludes that most faculty members surveyed did not change their preference for face-to-face teaching, yet many were amenable to using more online tools and slowly accepting additional technological formats. Increased institutional support, guidelines and training may offer a more positive experience for both educators and learners. Without such changes, unexpected future pivots may meet with similar educator frustrations.
\end{abstract}

\section{Introduction}

Universities and colleges started the spring semester of 2020 in the same way they started any other spring semester, with most faculty members at four-year institutions having never taught online [1]. Before the semester was half over, many schools had closed or moved to distance education in response to the global COVID-19 pandemic that rocked the world of education. In a very short timeframe, approximately $91 \%$ of faculty members nationwide had to move classes from face-to-face to some form of online learning [1]. In addition to worries about COVID-19's impact on their family and friends, these faculty members had to replan, reformat, reschedule and deliver their classes remotely. In a normal semester, faculty members make many decisions about instruction regarding assignments, lectures, demonstrations and readings. This past semester, they had to include decisions about at-home equipment needed to teach remotely, whether their course instruction should be synchronous or asynchronous, and what types of technologies best optimize teaching and learning. Furthermore, faculty members had to consider issues such as student access, assessment and engagement.

Traditional face-to-face courses such as math and statistics can be challenging and the quality of these courses is vulnerable to disruption [2]. Universities and colleges have spent years enhancing and supplementing face-to-face delivery of these topics to improve student success and retention. While the percentage of faculty members who taught an online course in the U.S. was slowly rising [3], COVID-19 forced all course instruction online. In a matter of weeks, faculty members were delivering these same materials remotely with students, parents, and administrators expecting equivalent learning outcomes despite the sudden change of delivery.

Online instruction in general has been wellresearched, and current literature has begun documenting and reflecting on the sense of urgency and stresses surrounding this sudden transition's impact on higher education. One researcher summed up the chaos by writing, "Let's be clear: emergency remote learning is not the same thing as online learning" [4]. This rapid change has provided many opportunities for educators and learners yet has also produced challenges. In one study, $56 \%$ of faculty reported using new teaching methods and two-thirds of those with no online teaching experience used new approaches following the online transition [5]. Another study pointed out that through thoughtful observation of both learner and educator issues, instructors may be able to improve the experience and 
favorability of online learning, using this pandemic as a catalyst for better immersive courses [6].

Recent studies also show that challenges associated with online instruction vary significantly by institution type, discipline and mind-set. Most importantly, even with this uptick in online delivery, educators continue to question whether online education produces student outcomes equivalent to inperson courses. One study found that many instructors entering the field of online education preferred to experiment with hybrid courses that draw heavily from personal interrelated motivating and inhibiting factors [7], an option not available during the COVID transition. In exploring online instruction, Abas and David [8] found that "if educators are not provided with adequate rewards or incentives, and if the compensation is no different from conventional teaching, educators may not be motivated to upgrade their skills in using technology". Another study found that as course performance gaps are recognized, it is important that universities institute early warning signs or screening and scaffolding to assist students as well as address educator concerns and needs [9]. In response to such concerns, recommendations have been made that institutions deploy online professional development opportunities for faculty and create awareness of student inequities [5].

Many recent studies focus on this sudden transition from the perspective of the learner, but little has been reported on post-secondary faculty members delivering courses taught traditionally face-to-face such as mathematics and statistics. The purpose of this study was to examine the impact of COVID-19 on higher education educators abruptly forced to move traditional face-to-face courses such as math and statistics to online e-learning formats. For this study, researchers asked the questions, How were mathematics and statistics instructors that traditionally teach face-to-face courses impacted by COVID-19 and the sudden shift to online instruction?, and How did the sudden exposure to online instruction affect their preference towards face-to-face versus online teaching?

\section{Data collection and sampling}

The research team developed a brief survey questionnaire to explore how the sudden shift to remote teaching impacted instructors in subject areas that traditionally have a high percentage of face-toface courses. To capture the experiences of instructors in real time, the survey was developed and administered at the end of the semester.

\subsection{Participants}

The survey used a convenience sample to enable a focus on post-secondary Mathematics and Statistics instructors. All math and statistics instructors at four colleges or universities in South and Central Texas, including part-time/adjunct instructors, were invited by e-mail to participate. Researchers obtained approval from each organization's Institutional Review Board prior to contacting participants. It is not known how many of the persons invited were assigned to teach during the spring semester of 2020, but all survey participants taught at least one math or statistics course during the semester.

\subsection{Survey instrument}

Faculty members on four campuses were asked to report on their experiences with online teaching and the amount of time they spent on class preparation for online versus face-to-face classes. To explore the impact that COVID-19 had on the use of technology in the classroom, respondents were asked to identify their use of certain technologies both before and after the pandemic began. They were also asked to respond to Likert-style items related to the challenges and their affective responses to teaching during the semester. The survey also included a few demographic questions.

Additionally, to give faculty a chance to offer their opinions on this complex issue, one open-ended question was included in this survey. The research team added this open-ended question to allow the faculty members to express opinions and concerns regarding their experiences. The researchers were especially concerned that the brief survey may not anticipate all the critical aspects of the distance education experience.

The questionnaire was completed by four graduate students to test the Qualtrics survey and assess the clarity of the questions. Normally, the questionnaire would have been used in a pilot study, but this step was omitted due to the time constraints of this study.

\subsection{Data analysis}

Statistical analysis for the quantitative portion of this survey was performed using $\mathrm{R}$ statistical analysis software (R Core Team, 2020) from the raw dataset collected through Qualtrics. Comparison of continuous variables (number of hours and number of technologies) was done with a one-factor analysis of variance (ANOVA) for age group (which had three categories), with an independent means t-test when comparing across gender, and with the paired t-test when comparing within a category or group at two different times. To evaluate a change in proportions among the instructors from the beginning to the end of the semester, McNemar's test was used. P-values of less than 0.05 were considered to be statistically significant. This survey also included one open-ended question: Please tell us your thoughts regarding your teaching experience this semester. Responses to this question were plentiful and offered strong insight on 
the opinions of faculty members upon completion of the semester. The comments were coded thematically in Dedoose, an online coding tool, which allowed researchers to extrapolate themes from the data using deductive and inductive coding [10].

\section{Findings}

The study attracted 51 participants out of 153 invited instructors, for a $33 \%$ response rate. The participants were relatively diverse in terms of education level, course load, gender, age, and experience. A substantial portion of the respondents provided comments for the open-ended question, with a broad range of opinions.

\subsection{General characteristics of participants}

The demographic questions revealed that $71 \%$ of the respondents were employed full-time by their institution, $51 \%$ had a $\mathrm{PhD}, 65 \%$ taught either one or two courses during the semester and the remainder taught three or more. By gender, $47 \%$ identified as female, $47 \%$ identified as male, and $6 \%$ preferred not to identify their gender. By age group, $24 \%$ were 24 to $39,28 \%$ were aged 40 to 54 , and $48 \%$ were aged 55 or older. The median amount of post-secondary teaching experience was 12 years, with a range from one to 45 years and an interquartile range of 7.5 to 20 years. In terms of online teaching experience, $23 \%$ reported being certified prior to the spring semester and $6 \%$ had attended some training related to online teaching, and thus $71 \%$ had no training or certification to teach online prior to the start of the semester. Further, 14\% of the respondents had taught one or two courses in an online or blended format and $15 \%$ had taught more than two online or blended courses.

\subsection{Additional hours spent on teaching tasks}

The reported mean time spent on course work for instructors who taught only one or two courses during the semester increased $52 \%$ from 11.4 to 17.3 hours per week (p-value $<0.0001$ by the one-tailed matchedpairs t-test). For the remaining instructors who taught three or more courses, their reported mean time increased $36 \%$ from 28.5 to 38.9 hours per week (pvalue $<0.0001$ ). Teachers reported an additional 4.2 hours per week on average learning to use remoteteaching technology or other tasks not directly related to course work.

Comments collected from the open-ended question supported these measured increases and several faculty members expressed frustration at the time spent. One faculty member called the semester's remote learning "an inevitable disaster during which faculty, staff, and students worked tirelessly to yield some non-negative outcomes." A small number of respondents found the overall experience only slightly discomforting. One described the experience as initially somewhat challenging, "however once we got into the swing of things, it worked out."

\subsection{Use of technology, by age and by gender}

Before the shutdown prompted by Covid-19, the youngest age group (24 to 39) used an average of 2.8 of the 8 listed technologies, and the other two groups used an average of 3.0 (no significant difference across age groups, $\mathrm{p}$-value $=0.53$ ). Males used an average of 3.3 technologies and females 2.6 (p-value $=0.045)$. By the end of the semester, the youngest age group reported using an average of 5.5 technologies, the middle group reported an average of 5.6 technologies, and the oldest group an average of 5.0 technologies, while males used 5.7 and females 4.9 technologies (no significant difference across age groups, $\mathrm{p}$-value $=0.22$, or across gender, $\mathrm{p}$-value $=$ 0.055 . However, within each age group, there was a significant increase post-pandemic in the number of technologies used ( $\mathrm{p}$-value $<0.0001$ ) from beginning to end, with the increase ranging from 2.0 to 2.7 additional technologies per group.

\subsection{Technology use before and after COVID- 19 transition}

At least $80 \%$ of instructors reported posting grades online, communicating with students via a course website, and posting homework online, before the transition. Eighteen percent reported giving online quizzes or tests. All other technologies listed on the survey were employed by $10 \%$ or fewer of the instructors at the start of the semester. By the end of the semester, $92 \%$ of survey participants had added online video platforms such as Zoom to their courses, $75 \%$ had added online quizzes or tests, and $57 \%$ had added instructional videos. Before the transition, only $4 \%$ of faculty communicated with their students via social media sites, including blogs. Afterwards, this number increased to $27 \%$.

Figure 1 below illustrates the percentage of faculty members using each of these technologies. The responses demonstrate the change in technological use pre- and post-pandemic. Note that there were rather dramatic increases in the use of online testing, videos, and video conferencing in response to the sudden shift to online instruction.

The results contrast with responses to the openended question, where many respondents revealed they felt ill-equipped to make the technological leaps required for the transition from face-to-face to online instruction. With limited training and only very short notice, several respondents struggled to incorporate various technological tools throughout the course of the semester. One participant found it "exhausting choreographing the dynamics in Zoom." 


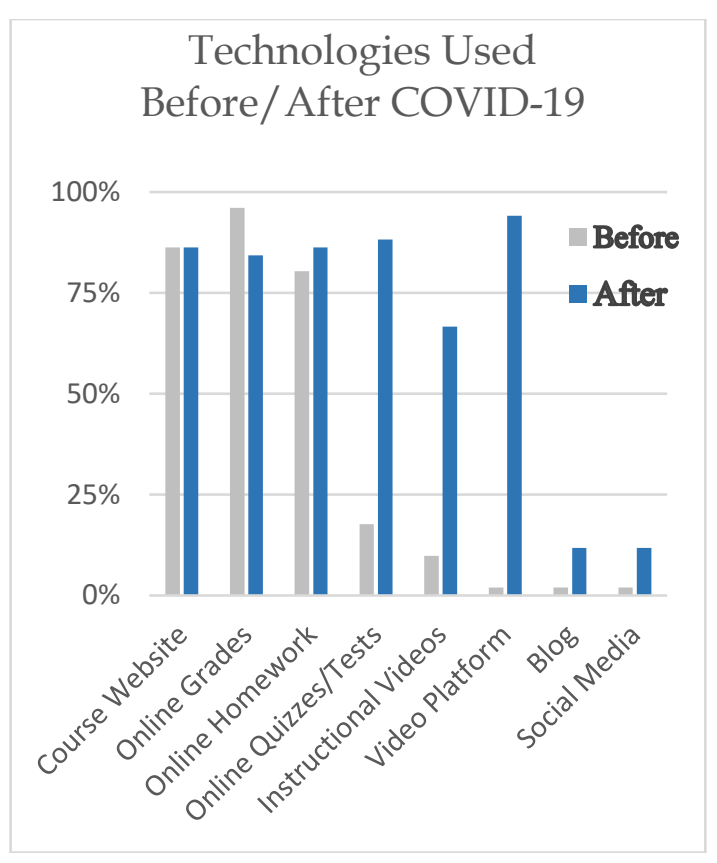

Figure 1. Technologies used before/after COVID-19

\subsection{Most often identified challenges to remote teaching}

Instructors were asked to rate 13 concepts as very challenging, somewhat challenging, or not challenging. To compare the concepts, items marked very challenging were assigned a score of two points, and somewhat challenging items were assigned a score of one point, with zero points assigned when not challenging was chosen. Thus, with 51 respondents, the maximum score a concept could receive is 102 , and the minimum score is zero.

Table 1. Identified challenges to remote instruction

\begin{tabular}{|c|c|}
\hline High & Score \\
\hline Testing & 83 \\
\hline Student to Student Interactions & 81 \\
\hline \multicolumn{2}{|l|}{ Medium } \\
\hline Instructor to Student Interactions & 66 \\
\hline Absenteeism & 63 \\
\hline Personal Teaching Style & 61 \\
\hline Student Connectivity & 58 \\
\hline Work/Life Balance & 53 \\
\hline Time Management & 48 \\
\hline Remote Office Hours & 44 \\
\hline \multicolumn{2}{|l|}{$\begin{array}{r}\text { Low } \\
\end{array}$} \\
\hline Whiteboard Use & 39 \\
\hline HW Assignments & 38 \\
\hline Instructor Connectivity & 32 \\
\hline Learning Management System & 16 \\
\hline
\end{tabular}

The concepts and their scores are shown in Table 1, grouped into High, Medium, or Low challenges based on their scores. The two concepts that were rated very challenging by two-thirds of instructors were the evaluation of students (testing) and encouraging students to interact with each other.

Three of the highest four medium challenges also directly involved the student: interactions between instructor and student, an increase in absenteeism of students, and online access (connectivity) for the student. The four concepts rated not challenging by half or more of the instructors were things an instructor had more personal control over: using the school's learning management system in a remote learning environment, instructor connectivity, assigning and evaluating homework, and coming up with a substitute for whiteboards.

Two of the top three identified challenges were frequently mentioned in the open-ended portion of the survey. Many respondents commented on the challenges they faced regarding testing, in reference to honor code violations. On instructor to student interactions, several faculty members wrote that teaching online interfered with their abilities to fully connect with their students, only one respondent commented on the challenges of encouraging students to interact with each other. While this study did not focus on how these changes impacted students, the researchers were able to glimpse how faculty members felt about the struggles their students faced as they struggled through the semester together.

\subsection{Rate of agreement on beliefs/opinions about remote instruction}

Further, instructors were asked to rate their level of agreement with three notions about their remote teaching experience: $69 \%$ agreed that the experience increased their comfort level with additional technologies when teaching math/ statistics; 55\% agreed that the experience enhanced their teaching style; but only $22 \%$ felt that online math or statistics courses can produce learning outcomes equivalent to that from face-to-face teaching. As well as being concerned about the efficacy of the experience, faculty members had mixed opinions about their experiences. One faculty member wrote, "I CANNOT wait for face-to-face classes to resume!," but another wrote, "(if) given the choice in the future, I think I would opt for online."

\subsection{Preference/willingness to teach online/ blended courses}

A total of 46 instructors (90\%) reported preferring to teach their courses exclusively face-to-face prior to the requirement to teach remotely, leaving five (10\%) willing to teach in an online or blended format. By the end of the semester, 14 additional instructors converted to a willingness to teach online or blended courses, for a total of 19 instructors $(37 \%)$. This 
increase is statistically significant with a p-value of 0.0005 using McNemar's test. It is interesting to note that five of the 12 online-certified instructors still did not prefer to teach online by the end of the semester, and that 12 of the 14 converting instructors were not certified prior to the semester.

\section{Discussion}

Studies have shown that successful remote learning programs require time to develop [11] [5], yet the pandemic forced university faculty across the country to scramble to provide online course delivery with limited preparation time. Many of these faculty entered uncharted waters, unprepared for and with limited knowledge of technologies and pedagogies used in remote instruction. During the start of this transition, Lederman [6] presupposed that many instructors faced with this sudden transition would probably be offering their students "nothing more than video conferenced lectures supplemented by emailed assessments." By surveying instructors at the conclusion of the Spring 2020 semester, researchers were able to explore the pandemic's impact on mathematics and statistics faculty and how the shift impacted their perspectives on remote instruction.

\subsection{Shift to remote teaching in response to pandemic}

The study's first question inquired about the personal and professional well-being of full and parttime faculty members that taught post-secondary mathematics and statistics courses primarily in-person before the pandemic. In response to the question How were mathematics and statistics instructors that traditionally teach face-to-face courses impacted by COVID-19 and the sudden shift to online instruction?, researchers identified three themes, addressing COVID-19's impact on faculty life/work balance, impact on classroom interactions, and use of technology in the classroom.

4.1.1. COVID-19's impact on faculty life/work balance. The first identified theme involves faculty life/work balance. Instructors responding to the struggles of the pandemic in their personal lives were also faced with the added stresses of abrupt changes in their professional lives as they struggled to adjust their courses to asynchronous and synchronous online learning. Results revealed that survey participants who taught one or two courses reported an average increase of $52 \%$ in the number of hours spent preparing for courses and instructors who taught three or more courses reported an increase of $36 \%$.

Comments to the open-ended question exposed how professional challenges were often compounded by personal stressors related to the pandemic. Some respondents felt that, in addition to the increased hours spent in training and preparation, there was a marked increase in time spent emailing, listening to, tutoring and in general responding to the needs of students. In describing the differences before and after the sudden shift to remote teaching, one faculty member described spending "a lot of time assisting with math issues or questions on zoom, providing an ear, or consoling students. During normal semester this occurs randomly, but this semester, it was the daily norm." Another respondent summed this sentiment up best by writing:

Grading and responding to student work in a timely fashion is important. Grading and providing feedback take more time (with remote instruction) simply due to the fact that it takes more time to open, edit, respond to submissions electronically than using paper and pencil. It could take up to five times as long depending on the structure of the assignment.

Further, some faculty members expressed that the continuous need to respond to student issues made it feel like there was no break between home and work. Still others described the struggles of balancing the increased demands of learning and preparing for online instruction with the demands of caring for young children and caring for elderly family members. Reflecting on these challenges, one participant wrote, "The most challenging aspect was trying to teach and keep up with other work while having a small child at home due to cancelled daycare. It seems like this should be part of any conversation around the impact of COVID-19."

Studies on COVID-19 and its impact on higher education are emerging and a few have identified similar challenges. For example, several studies found that oftentimes throughout the semester, faculty were overwhelmed and in need of better guidance $[1,5]$. Several highlighted the importance of focusing on short and long-term professional development to better support faculty as they prepared for the upcoming semester [1]. Respondents surveyed by Johnson, Veletsianos and Seaman [5] sought guidance on working from home, particularly while taking care of young children. Prior to the pandemic, Perry and Steck [12] argued for the need for faculty to develop better boundaries and to hone their time management skills in order to more effectively deal with students who expect their instructors to be available continuously. These studies align with the comments from the respondents in the current study.

4.1.2. COVID-19's impact on class interaction. The next theme to emerge involves the post-pandemic changes that occurred in the interactions between instructors and learners. As noted above, the top three challenges identified by respondents involved classroom interactions: testing, student to student 
interaction, and interactions between instructor and student. Overall responses to the open-ended question support these findings. Regarding instructor to student interactions, several faculty members found it challenging to engage with students online, particularly when students did not follow class instructions, did not turn in assignments on time, did not unmute themselves during online discussions, and did not read emails. "The biggest issue was my students not taking responsibility for their learning," wrote one participant. Another felt that "teaching requires interaction, and video-conferencing is a poor substitute for face-to-face communication."

Although student to student interactions were hardly mentioned in these comments, many respondents mentioned exams in reference to honor code violations. Several surveyed participants expressed frustration over giving assessments in an online environment, with one commenting that "students have taken advantage of the system that does not proctor their testing." Another respondent wrote that it was "unfortunate that I no longer trust students to do their own work independently." Still another described how rampant cheating resulted in "automatic-F's to about $20 \%$ of students in my classes." A few faculty members mentioned that giving exams seemed to trigger mysterious student connectivity issues that seemed not to occur at other times. One instructor encouraged researchers conducting this study to consider collecting data solely on the issue of student integrity. Suspecting significant and rampant integrity violations, one respondent wrote, "In one of my classes, students submitted the final exam questions to (an online) website and a person who works for them produced and posted the answers to the question."

The challenges identified raise concerns that students will be ill-prepared for subsequent math courses since math courses tend to build on knowledge acquired in previous math classes. They also stress the importance of finding solutions to minimize honor code violations during assessments. While several participants commented on their frustrations regarding honor code violations during quizzes and exams, few offered solutions to this complex problem. One respondent felt the only option for assuring the integrity of exams was to require students to take tests on campus. Another acknowledged the importance of rethinking the nature of evaluations, describing the process as taking a considerable amount of time but acknowledging its importance.

Similar challenges related to the impact of COVID-19 on online instruction were exposed by additional researchers. Johnson, Veletsianos and Seaman [5] reported that nearly half of the instructors they surveyed lowered the volume of student coursework. Another report found that three out of five instructors they surveyed faced significant challenges with keeping students engaged and that several faced similar honor code issues such as students "magically earning higher grades than before [1]." Still another, exploring one institution's response to academic integrity during the pandemic, put the onus of this complex issue on faculty, student and for-profit commercial contractors poised to make huge profits [4]. First, the author argued that many honor code violations stemmed from the fact that faculty members shifting to remote teaching had little time to consider the implications of how face-to face assessments should differ from online testing, leaving then unprepared to handle the consequences. Second, Eaton [4] highlighted student immaturity and learner stresses related to the pandemic as important variables contributing to honor code violations. Finally, Eaton [4] argued that the problem was magnified by "the cheating cartels ready to seduce them with false promises of help."

The current study did not specifically survey faculty perceptions on learner challenges, yet responses to the open-ended question revealed that several respondents were sympathetic to the struggles of their students. One respondent acknowledged the fact that neither faculty nor students signed up for the sudden conversion of face-to-face courses to online learning. "Learning from home, when all other children and other adults are home, meant trying to learn in a noisy environment and keeping their microphones on mute to protect other classrooms from potential noise," wrote one respondent. Another expressed concern that "students were really struggling mentally." Finally, one faculty member, a non-native English speaker, recognized that students in the classes may have difficulty understand the instruction and content of a course delivered remotely as opposed to face-to-face. Similarly, faculty members in other recent studies often expressed concerns for the well-being of their students during this difficult time [5].

\subsubsection{COVID-19's impact on use of technology in} the classroom. The final theme to emerge from this study involved the pandemic's impact on the use of technology on mathematics and statistics courses. Technology in the classroom has been extensively studies, particularly regarding online instruction [13], yet the sudden shift forced many professors to scramble to develop or hone their knowledge regarding technological applications for online instruction [6]. To explore technology in the classroom, surveyed faculty members were asked questions about the technologies they utilized in their courses both before and after the pandemic.

In writing about their struggles with technology, some participants of this study discussed their struggles with connectivity, the challenges of creating and uploading videos, and the lack of or limited access at home to equipment they required for online 
instruction. In describing the challenges of setting up video conferencing for online course delivery, one respondent wrote, "I didn't know how to use my phone as a doc cam, but more importantly, I didn't have the proper cords and such." Another respondent found online teaching stressful because of the need to "handle the intricacies of the online LMS . . . students seemed to think that as instructors we would have a $100 \%$ understanding of how things would look for them and play out."

Faculty members were asked to identify the types of technology they utilized in the classroom pre- and post-pandemic. Before to the shutdown, only $29 \%$ of respondents in this study had participated in any trainings or certifications to teach online. Still, $96 \%$ of the respondents reported posting grades online, $86 \%$ reported communicating with students via a course website, and $80 \%$ of the faculty surveyed reported posting homework online. These figures indicate that almost all respondents had some basic familiarity with their campus LMS. After the sudden switch to online instruction, the most frequently added technological tools were online video platforms such as Zoom and Adobe GoToMeeting, and LMS tools that provided online tests and quizzes.

Pre-pandemic, only one instructor utilized an online video platform in their courses. By the end of the semester almost all instructors had added an online video platform to their courses, but a few $(8 \%)$ of the respondents did not. Researchers can only assume that they may have opted to conduct their courses solely asynchronously. In addition, after the shift threefourths of the instructors added online quizzes or tests, and over half added the use of instructional videos. Twelve respondents started blogging or using other forms of social media after the transition to improve classroom communications. This seems to indicate when circumstances outside their control tipped the balance toward a necessity to gain more skills, the mathematics and statistics instructors surveyed quickly overcame the learning curves needed to incorporate new technological tools into their remote course delivery. Interestingly, one national study pointed out that while instructors were learning new technologies for the courses they taught, oftentimes students also had to learn a variety of technological tools, instructor approaches/communication, but for five different courses [1].

Comments in response to the open-ended questions offered insight into how participants of this study felt about the technological trainings and support they were offered by campus administration. With minimal notice, many faculty members, especially those with no online teaching experience, scrambled to learn technology associated with remote instruction. A few respondents expressed gratitude for the "crash course" to online technologies, including online trainings, access to instructional videos, peerto-peer mentoring, and ongoing follow-up support.
While some found the assistance offered by their administration and peers helpful, a few expressed disappointments in the administrative response. Overall, $69 \%$ of the mathematics and statistics faculty members surveyed for this study agreed that the experience increased their comfort level with incorporating technologies in their courses. In general, faculty that commented favorably on the support and training they received were more likely to respond favorably to the sudden switch.

Offering guidance specific to technology within mathematics courses, the National Council of Teachers of Mathematics [14] wrote, "Technology is essential in teaching and learning mathematics; it influences the mathematics that is taught and enhances students' learning". Pushing for more technology in the classroom, De Freitas and Spangenberg [15] argued that mathematics instructors need more professional development and training on technological pedagogical content knowledge to enhance instructor effectiveness and promote better mathematics education. David, Seddon, Harlow and Brown's [16] study shows that teaching statistics online can also be enhance by technology. In 2011, Christchurch, NZ experienced a severe earthquake. In response to this, instructors at the University of Canterbury moved their introductory statistics classes to a hybrid model. In their two-year study on the quake's impact, David et al. [16] concluded that instructors reported that their primary concern was that the students stay "connected," and recommended the use of innovative technologies to monitor student progress and improve instructor/student engagement. Although available technology has changed since 2011, these findings still ring true today.

Despite the benefits, some researchers offer words of caution regarding technology in the classroom. In their research on incorporating technology into online instruction, Steele, Holbeck and Mandernach [17] argues that technology is only as useful as the selfefficacy of the faculty and that ultimately, technology's inclusion will only impact student achievement if it is used for a significant purpose. Another researcher points out that educators must understand how to integrate and utilize the technological tools available to them if technology is to enhance student learning [18]. Finally, in describing interactions between learners and technology in mathematics courses, Cullen, Hertel and Nickels [13] offer the reminder, "Students need to learn how to use the technology, but it should not be at the cost of losing sight of the mathematics."

\subsection{Rate of agreement on beliefs/opinions about remote instruction}

Recent data suggests that as more post-secondary instructors gain online teaching experience, many faculty members are slowly accepting the legitimacy 
of online instruction [3]. The second question in this study explores the opinions of post-secondary mathematics and statistics instructors accustomed to in-person teaching on the subject of online instruction. In response to the question How did the sudden exposure to online instruction affect their preference towards face-to-face versus online teaching?, respondents answered how the transition impacted their personal teaching style and student learning outcomes.

Results show that $71 \%$ of surveyed participants began this transition without any training or certification to teach online. Yet despite their collective limited experiences, more than half (55\%) of all surveyed participants agreed that the semester enhanced their teaching style. In a similar study, $75 \%$ of faculty felt the sudden transition to remote instruction made them better instructors [1]. Prepandemic studies also showed that many instructors felt online teaching helped them think more critically about ways to engage students [3]. Certainly, studies held prior to the pandemic were more likely to involve instructors that had ample time to prepare their classes.

Surprisingly, only $22 \%$ of the respondents in this study felt that online math or statistics courses could produce learning outcomes equivalent to in-person instruction. Perhaps this low number is reflective of the challenges associated with honor code violations. Or perhaps meeting the objectives of the course was an unrealistic expectation given the semester's parameters, a sentiment expressed by one respondent. There are limited studies on this topic and results are mixed. Some researchers conclude that student learner outcomes can be equally achieved by both remote and traditional learners [19]. On the other hand, others report that many faculty members remain skeptical that remote course delivery can produce learning outcomes as equivalent to face-to-face [3] [5].

In exploring faculty member preferences to teach face-to-face versus online, this study shows that before the pandemic, only $10 \%$ of the instructors had a preference to teach online. At the end of the semester, an additional $27 \%$ were willing to teach online, which reflects the slow acceptance findings of Jaschik and Lederman [3]. Participant comments on this issue were mixed. While a few expressed satisfaction with the experience, many others expressed dismay. One respondent called the sudden transition to online teaching "a great experience" and another wrote, "It was an adventure!" These positive comments were outweighed by comments such as "mathematics faculty had nightmares" and "it is my sincere hope that anyone who previously advocated for online learning as a panacea has changed their minds, at least in the case of mathematics."

Finally, another major finding that emerged from this study is that by the end of the semester, faculty members were already looking toward the future, writing introspective comments that often began with the phrase "If I were to do this again, . ..." Upon reflection, some instructors stated this experience made them rethink some of their strategies for faceto-face instruction. Based on lessons learned through this experience, others decided to adapt their syllabi going forward to restructure assignments/assessment ratios and to diminish the need to "always feel plugged in and accessible to my students." Whereas some faculty members listed concrete examples of changes such as placing student in the same groups each week to encourage unity as well as learning to use a phone as a document camera, others listed more reflective goals such as needing to contemplate on ways to finding better balance between life and work, and the need for tools to be set in place before the start of the next semester to address these complex issues.

Reflecting on this transition also creates an opportunity for mathematics and statistics faculty to explore resources that offer strategies for online and technological pedagogies [17] [20]. Trenholm, Alcock and Robinson [20] argue that teaching a math course online should not simply replicate face to face instruction and that focus on online "might be exactly the right moment for researchers to effect a move to more student-centered pedagogies."

\section{Limitations and further study}

The impact of the pandemic on students and their learning outcomes is a worthy subject to study, but this paper asserts that more research is needed to understand the experiences of faculty members during this difficult time. Researchers have identified two limitations to this research. The first limitation involved the focus on math and statistic faculty. While the researchers chose to focus on math and statistics instructors because they traditionally teach face-to-face courses, there are certainly other faculty in other disciplines that also traditionally teach in the classroom. Researchers suggest future studies survey faculty that self-identify as teaching traditional faceto-face courses.

Second, although the COVID-19 pandemic will end someday, the nature of post-education instruction and learning will likely be changed forever. It is imperative that researchers learn as much as possible from the experiences of faculty members and their sudden pivot to remote instruction, although this may prove difficult as future research on this semester will be affected by faculty impressions, abilities, experiences, and satisfaction with distance education that will most likely change in subsequent semesters. Additionally, further research, such as a longitudinal study, should assess the improving efficacy of these faculty members and guide the continuous improvement of online math education. 


\section{Conclusion}

The COVID-19 pandemic resulted in drastic changes for education that included a move from faceto-face instruction to a virtual environment midway through the Spring 2020 semester. For many instructors in higher education, this was a move to an unfamiliar, stressful environment. The goal of this study was to develop a clearer understanding of the stresses and struggles post-secondary mathematics and statistics educators faced through this unexpected, abrupt migration. In order to measure these impacts, the researchers developed a survey questionnaire to collect quantitative and qualitative data from instructors. The survey was administered at four institutions in South and Central Texas during the semester and 51 faculty members responded.

Results of this survey underscored the strong impact COVID-19 had on the well-being of respondents in both their professional and personal lives. Despite being overwhelmed and receiving no added financial benefit, faculty members still expressed concern for the well-being of their students. Armed with newly honed technological skills developed during this transition, and reflecting on their experiences, a small proportion of the instructors looked forward to the opportunity to teach remotely again, yet most expressed frustration, caution and concern, with one commenting, "Fingers crossed that face-to-face instruction can resume in the Fall." The wide variety of responses from these faculty members revealed that while many participants agreed that the online semester enhanced their teaching style, more felt that online instruction could not produce learning outcomes equivalent to in-person instruction. The sudden pivot to online instruction only slightly impacted faculty willingness to teach online.

Recent research suggests that regardless of the reason behind the sudden shift to online course instruction, student success ultimately rested with faculty members and the quality of their course delivery [12]. Others argue that faculty should be given a break for the mistakes they may have made during their sudden pivot to online instruction [5]. Ultimately, no one knows what the future holds for post-secondary synchronous and asynchronous learning in the upcoming months. By utilizing this transitional semester as a learning tool, university faculty and administrators can better strategize how to increase the well-being of instructors and meet the needs of remote learners going forward. When the pandemic recedes and this online teaching experiment can be reflected upon, it will be interesting to note if other attitudes and impressions have been impacted by this hasty remedy.

\section{References}

[1] Fox, K., Bryant, G., Lin, N., Srinivasan, N. (2020, July 8). 'Time for Class - COVID-19 Edition Part 1: A National Survey of Faculty during COVID-19', Tyton Partners and Every Learner Everywhere; http://www.everylearnerevery where.org/resources (Access Date: 20 July, 2020).

[2] Kuhfeld, M. \& Tarasawa, B. (2020). 'The COVID-19 slide: What Summer Learning Loss Can Tell Us about the Potential Impact of School Closures on Student Academic Achievement', Northwest Evaluation Association (NWEA). https://www.nwea.org/content/uploads/2020/05 /Collaborative-Brief_Covid19-Slide-APR20.pdf (Access Date: 22 July, 2020).

[3] Jaschik, S. \& Lederman, D. (Eds.) (2019). '2019 Survey of Faculty Attitudes on Technology', Inside Higher Ed, https://www.ship.edu/globalassets/idwt/faculty/professiona 1_development/newsletter/ihe_2019_faculty_tech_survey_ 20191030.pdf (Access Date: 20 July, 2020).

[4] Eaton, S. E. (2020). 'Academic Integrity during COVID19: Reflections from the University of Calgary', International Studies in Educational Administration (Commonwealth Council for Educational Administration \& Management (CCEAM)), 48(1), 80-85.

[5] Johnson, N., Veletsianos, G., \& Seaman, J. (2020). "U.S. Faculty and Administrators' Experiences and Approaches in the Early Weeks of the COVID-19 Pandemic", Online Learning, 24(2), 6-21.

[6] Lederman, D. (2020). 'Will Shift to Remote Teaching Be Boon or Bane for Online Learning?', Inside Higher Ed. https://www.insidehighered.com/digital-

learning/article/2020/03/18/most-teaching-going-remotewill-help-or-hurt-online-learning (Access Date: 25 July, 2020).

[7] Terantino, J. (2020). "Exploring Factors that Impact Faculty Decisions to Teach Languages Online: Is It Worth the Individual Return on Investment?", Online Journal of Distance Learning Administration, 23(1), 1-18.

[8] Abas, M. \& David, A. (2019). "Teachers' Selfassessment Towards Technology Integration in Teaching Mathematics", International Journal for CrossDisciplinary Subjects in Education, 10(2), 4068-4079.

[9] Xu, D., \& Jaggars, S. S. (2014). "Performance Gaps Between Online and Face-to-Face Courses: Differences Across Types of Students and Academic Subject Areas", The Journal of Higher Education, 85(5), 633-659.

[10] Miles, M. B., Huberman, A. M., \& Saldaña, J. (2013). Qualitative Data Analysis: A methods sourcebook. SAGE.

[11] Aust, P., Thomas, G., Powell, T., Randall, C. K., Slinger-Friedman, V., Terantino, J., \& Reardon, T. (2015). "Advanced Faculty Professional Development for Online Course Building: An Action Research Project", Internet Learning Journal, 4(2), 103-118. 
[12] Perry, D., \& Steck, A. (2019). "Changes in Faculty Perceptions about Online Instruction: Comparison of Faculty Groups from 2002 and 2016", Journal of Educators Online, 16(2).

[13] Cullen, C. J., Hertel, J. T., \& Nickels, M. (2020). "The Roles of Technology in Mathematics Education", The Educational Forum 84(2), 166-178.

[14] National Council of Teachers of Mathematics (NCTM). (2000). Principles and Standards for School Mathematics', https://www.nctm.org/Standards-andPositions/Principles-and-Standards/Principles,-Standards,and-Expectations/ (Access Date: 1 Aug, 2020).

[15] De Freitas, G., \& Spangenberg, E. D. (2019). "Mathematics Teachers' Levels of Technological Pedagogical Content Knowledge and Information and Communication Technology Integration Barriers", Pythagoras, 40(1), 1-13.

[16] David, I., Seddon, H., Harlow, J., \& Brown, J. (2019). "Teaching Statistics in a Crisis Zone", In Proceedings of the Eighth International Conference on Teaching Statistics, Ljubljana, Slovenia. Voorburg, The Netherlands: International Statistical Institute.

[17] Steele, J., Holbeck, R., \& Mandernach, J. (2019). "Defining Effective Online Pedagogy", Journal of Instructional Research, 8(2), 5-8.

[18] Srisurichan, R. (2012). Teachers' Accounts of Successful Technology Integration in Teaching Mathematics (Publication No. 3512485) [Doctoral Dissertation, The University of Wisconsin - Madison]. ProQuest Dissertations Publishing.

[19] Brinson, J. R. (2015). "Learning Outcome Achievement in Non-traditional (virtual and remote) Versus Traditional (hands-on) Laboratories: A Review of the Empirical Research", Computers \& Education, 87, 218237.

[20] Trenholm, S., Alcock, L. \& Robinson, C. (2016). "The Instructor Experience of Fully Online Tertiary Mathematics: A Challenge and an Opportunity", Journal for Research in Mathematics Education, 47(2), 147-161. 